\title{
MACHINE DRAWING: TROUBLES AND OPPORTUNITIES IN MANAGING LABORATORY ACTIVITIES IN AN ONLINE CLASSROOM
}

\author{
Sergio RIZZUTI and Luigi DE NAPOLI \\ University of Calabria, Italy
}

\begin{abstract}
Since Learning Management Systems (LMS) appeared some 20 years ago, their experimentation grew slowly, compared with the explosion that occurred after the Covid-19 emergency. Due to the closure of schools and universities worldwide, every educational institution and their teachers had to move towards the usage of LMSs for Online Distance Learning (ODL). This obliged the teachers to quickly familiarize with such kind of didactics and every kind of course faced these new opportunities. Machine Drawing is a course that requires much interaction between teachers and students and may not exploit validly many modalities invented in LMS. This paper presents the experiences done implementing online didactics, trying to apply all the online tools to the traditional way of teaching. Mainly laboratory activities, made online, must reproduce the interaction made in-person. Nevertheless, online connections opened new ways to try stricter relationships between the teacher and those students, who have less skill, even shyness, and then may accumulate delays. Differentiating the way in which didactics (lecture and laboratory) may be delivered, some traditional techniques have been improved. Employment the video recording of all activities done has given students the opportunity to repeat the more delicate steps of some topics. The check online of designs and elaborations by instructors allows students to be more concentrated on explanation, which may be done collectively or singularly.

Comparing the results of exams before and after online didactics revealed that the number of students that passed the exam and the average of reached grade grew significantly.
\end{abstract}

Keywords: Machine drawing, online classroom, virtual class

\section{INTRODUCTION}

Pandemic Covid-19 emergency has sped up universities towards the adoption of Learning Management Systems in order to avoid the physical interaction of students, among them, and with teachers $[1,2]$. Several are the software platforms able to build virtual classes in which the relationship between people is mediated by the web. In the specific case of Machine Drawing teaching, the organization of the course syllabus creates a lot of problems to the three types of conjoint activities that must be scheduled: lectures, laboratory, and tutoring.

Lectures are typically made as one-many relations. Really teachers explain the arguments with little interaction with the audience.

Tutoring is a one-one relation, in which every student has the opportunity to ask for clarification on not understood or misunderstood topics.

Laboratory is the moment in which the hands-on learning activity is performed and when the knowledge of all significant topics related to machine drawing and design is transferred: how to think about an architectural arrangement of components to reach a design solution for an engineering problem.

This last one would have been really problematic if it were not done with in-person meetings. Till now, in fact, the course of Machine Drawing has been performed, always in wide classrooms with many tables with many students around them and with teachers that exchange information with single or few persons at a time. The authors began to employ Microsoft Teams ${ }^{\mathrm{TM}}$ to manage the virtual class when pandemic emergency started, with all activities performed online. The paper describes the way in which the whole teaching and overall laboratory has been performed.

In order not to lose the manual nature of most of the activities, the hardware setup continues to be blackboard-friendly. The teacher uses hand drawings, both on a sheet of paper and on the blackboard, 
positioning a webcam in such a way that students, online, can follow the talks from a point of view very similar to that of the teacher.

The paper describes the new organization that have been implemented in two courses of Machine Drawing in two Bachelor Degrees: Mechanical Engineering and Management Engineering.

The new courses organization will be compared with the old ones. The assessment of the quality of participation and of the exams result is done only for the Management Engineering course, which completed in the first semester.

\section{GENERAL ORGANISATION OF THE COURSES}

Both courses of Machine Drawing are positioned at the second year of the Bachelor Degree. It is a 12 ETCS for the Mechanical Engineering curriculum and 6 ECTS for the Management Engineering one. The Course for Mechanical Engineering is organized along the whole academic year and is divided in two modules.

The first module is addressed to the basis of design, drawing typically single parts. The second module is focused on the assembly design. The topics range from geometric construction to orthogonal projection, from axonometric representation to sections, from identification of true geometric form of objects to the development of their surfaces, dimensioning. The connection between the two modules in which is subdivided the course consists in the first step of the reverse engineering process in which students have to make a drawing from a real object. This activity allows students to apply for measuring by a calliper, recognize the true dimensions, organize the viewpoints for $2 \mathrm{D}$ and axonometric representation. Studying the morphologic aspect of an object, the embedded manufacturing processes and their errors are revealed. This allows the teacher to introduce almost naturally the concepts of tolerancing, even dimensional as geometrical. The work continues with design for manufacture, geometric dimensioning and tolerancing, stack up tolerances, identification, and functionalities of typical machine components.

The week schedule is as follows:

$3 \mathrm{H}$ Lectures $-2 \mathrm{H}$ Practice $-2 \mathrm{H}$ Laboratory.

$3 \mathrm{H}$ Lectures held in one day in which the theory is explained with all the elements necessary to implement it.

2H Practice on CAD in which Autodesk Inventor ${ }^{\mathrm{TM}}$ modeler is introduced to students with the task to become skilled in solid model and "drawing" of single parts and/or assembly.

$2 \mathrm{H}$ Laboratory where all the topics are elaborated by examples and performed by the usage of traditional tools or freehand.

All the pre-pandemic activities were performed in classroom by physical interaction between instructors and students.

Due to the pandemic Covid-19 emergency, all the activities have been transferred online. The software employed in this new way of teaching is Microsoft Teams ${ }^{\mathrm{TM}}$. Learning has changed the aspect due to a different relationship instructors-students, considering that people do not share the same physical space of a classroom. The classroom has become virtual, and communication was possible only by means of tools and internet connection.

Microsoft Teams was configured for online teaching. The Team "Machine Drawing" contains several channels: Lectures, Practice on CAD, and Laboratory. Students are invited to attend one of these activities in a meeting following the weekly schedule.

The same organization has been provided for the Course for Management Engineering that lasts only one semester.

\section{MACHINE DRAWING COURSES: LABORATORY ONLINE}

The 2H Laboratory continues to be divided into two shifts [A-L] [M-Z], in order to manage a limited number of students per shift. The numbers of students in the class has historically been the problem that affected the communication for this kind of course. Contrary to all other courses of the engineering studies, to guide students to be skilled for drawing involve a great number of contexts: cognition, abstraction, identification of forms, the relationship between sign and signifier.

The Laboratory is the time where all practical problems are faced and neatly explained to all people for the first time and then, to each people individually how many times is required.

During the pandemic emergency, the laboratory has been performed online, collecting students in channels of Teams, where all appeared in their place with their work in progress. Each webcam was on 
to show both the student and his/her work. The instructor had the possibility to see all students in a collection of pictures. Along the time of $1 \mathrm{H}$, each student had the possibility to show his/her work if this required a refinement or if there was any point not well understood.

Collecting the problems that emerged during the first part of the time instructor had the possibility to explain or repeat some concepts not well understood, or correct typical mistakes. This part is oriented to solve collective problems that involve a great number of students.

In case of some very complex mistakes, each student was invited to an individual meeting in a different channel dedicated to "meeting online", where, at a different time, other than that of the course schedule the root of the problem was identified. Such individual meeting is necessary because otherwise, if class time is employed, many other people may distract their attention and the time is wasted. More than inclass teaching, the online performances may have many sources of distractions, that remain hidden to the instructor, that may continue to talk about some topics whereas people may be occupied in others.

\subsection{Homework}

Every two weeks a new homework is assigned. The task is assigned as an "Activity" on Teams, with a deadline well declared. During this time, students may work at home and during the Laboratory.

After the conclusion of the activity, the works must be loaded on Teams. The works are corrected, and an assessment is sent to students.

Homework's are designed to grow competencies in drawing and are a prerequisite to attend the exam. The assessments done along time do not contribute to the final grade. The drawings assigned as homework are instead used also as a starting point of the discussion in the oral part of the exam. If sometimes, and it may occur, some mistakes remained on drawings, students are invited to correct them in real-time.

\subsection{Laboratory activities organization}

The Laboratory starts when the instructor opens a session on Teams, in the proper channel. The instructor explains the key points of the drawing, opening a file or an app that contains suitable materials. $\mathrm{He} /$ she may draw something by freehand, capturing the scene by a webcam positioned orthogonally to the sheet of paper or the blackboard. Sometimes lectures have been performed by teachers in the classroom alone, without an audience in person, using a webcam that catches what is sketched on the blackboard.

Students, in order to show their works, previously have to take a photo of the drawing on which they are working. The photo must be clear, with no distortion, and well illuminated without shadows. This image file may be uploaded to the repository on Teams, where it may be opened by the teacher using e.g., Autodesk SketchBook ${ }^{\mathrm{TM}}$. At this point instructor may write, draw, or highlight the elements that require adjustments, insights, or big changes.

This revision is performed on one drawing at a time, and it is explained to all the audience, i.e., to all the people that are connected at that time.

Really interesting in all the activities performed online is the possibility of recording the event in a video. This may be reproduced by each student at any time in asynchronous mode and repeated as many times as they want.

\subsection{Relationship teacher-students}

On the contrary of teaching in presence, where all the activities are performed in a classroom and the relationship among the attendees is direct and at close contact, online methodologies physically separate persons and at the same time make their relationship closer [3,4].

This is a surprising contradiction. Feeling close but being really distant at an unknown place.

What remains always the same is the time when the meeting occurs. People decide to share the time and the meetings became a happening where different relations may be started.

\subsubsection{Relationship one-many}

Typically, a lecture is characterized as a relationship one-many. The teacher starts the lesson at an established time and waits that all students registered at the course connect themselves to the channel. The talk may be direct, speaking straightforwardly, or opening documents/images to be shown. Each event is recorded by Microsoft Stream ${ }^{\mathrm{TM}}$ and reopened at a second time to see it again. It is necessary 
to check frequently if the audience is proactive, asking students questions and checking if something requires to be repeated or explained in a different way.

\subsubsection{Relationship one-one with audience}

The task of the laboratory consists of supporting students to understand the topics they have listened to in lessons and to implement those topics in drawing exercises proposed in assignments. Each assignment has been conceived as a set of steps towards the final management of an assembly. Throughout the year a set of 8-10 assignments are proposed to students. For the Management Engineering course, which lasts one semester, the set is composed of 8 assignments.

One of the assignments, in both courses, consists of generating a drawing of an actual component by means of the reverse engineering techniques. The objects that have been proposed this year have been "Lego ${ }^{\mathrm{TM}}$ bricks". Students had to reproduce in a drawing two bricks that they had to measure by a calliper and draw as a single part and as an assembly. The difficulty of such activity is strictly related to "online didactics". Generally, in presence, a limited group of students (a team of $3 / 4$ people), each at a time, uses measurement instruments of the Department workshop. Now, working online, it is necessary that everyone, individually, has a calliper and two bricks available in the place where they are working and are connected. Each student, online, should gather information by taking measurements and organize the representation.

All the assignments have been reviewed in the virtual classroom, discussing the drawings made by students. For each assignment, a set of up to 20 students have been raffled off, which delivered the solution to the instructor for a succeeding discussion in a live online session. All the delivered solutions, previously examined by the instructor in order to find, mark and classify the errors, have been illustrated and commented on. The major and more significant mistakes are presented, examining each assignment delivered and speaking directly with the author. Nearly all the typical mistakes that can be made in each type of task have been identified among all the deliveries. Besides the "one-one with audience" meeting, an errata/corrige file that collects all such typical errors in each assignment is added to the repository of Teams, to be consulted by students every time they feel it necessary and commented on by the instructor in the laboratory session.

Observing each drawing, the instructor intervenes by talking with the responsible student, considering that all other students connected have the possibility to listen to suggestions. This kind of relationship, which in presence could have been possible only interacting with very few people at a time, required that such answers should have been repeated many times, boring the instructor with such repetition.

Now new dynamics may be used. The relationship one-one with the audience does not put a limitation on the dimension of the audience. This gives more enthusiasm to teachers, considering that even a question has to be repeated, this can be done from different points of view, and this enlarges the argumentation, even introducing concepts not previously considered. Thinking also to the video recording of the session, all reflections made during the laboratory may be listened to again and this shortens the time of task completion.

\subsubsection{Relationship one-one alone}

During the laboratory, some personal difficulties may emerge, that teacher observed for a limited number of students. This is the time to activate a personal relationship instructor-student, organizing a separate session, other than the week timesheet of the course. A suitable team of "student receiving" is organized, where these students are invited to attend. During such sessions, more freely, the problems that emerged during the laboratory may be faced. Video recording is not necessary, now, because all the suggestions, that are shown on notebook display, may be directly captured by students.

A typical drawback of online didactics is the loss of discretion, in that a lot of people, when they would ask for something, are conscious in advance that many people can hear that. This kind of people lives badly such loss of "privacy", for shyness probably, and continues to accumulate unresolved problems. This special team has been created to allow such kinds of person to be involved in the process of learning. The time occupied in this activity must not be considered a waste of time, because drawing is a process that requires a special motivation, and this must be sustained in all ways.

\subsection{Laboratory activities deployment}

In order to achieve the proper preparation for the exam, the student is required to carry out some tasks at home, with increasing difficulty; these consist of 10 assignments, which are made with traditional 
tools, and someone in addition with 3D CAD. Each assignment is correlated to the lectures just delivered, which have been presented by the teacher, pointing out the crucial aspects in specific subtasks.

The presentation of each assigned homework is done in the virtual classroom according to a typical onemany relationship, conveyed by the web.

Each assignment has a deadline every two/three weeks, along the course, and the process of delivering the files related to the homework (both input and output) is implemented by means of "Activity" in Microsoft Teams ${ }^{\mathrm{TM}}$.

Much of the work employed by the teacher consists of reviewing the assignments using a graphics tablet and suitable software and this is also done online, operating on scans of drawings produced by the students, or by showing a live session on the way to solve a drawing problem. All the events may be recorded for offline learning activities.

If the teacher finds particularly scant drawings, he/she calls the correlated student for a one-on-one meeting, in order to solve these major flaws.

The exam can only be accessed if the assignments have been completed, then verified and endorsed offline, step by step, by the teacher.

When the course is delivered over two semesters, the teacher may verify the level of preparation achieved by the students by proposing an intermediate test at the end of the first semester, non-binding for the final grading, in order to assess the possibility, eventually, to recall and refine some topics.

\subsection{Practice on CAD}

Conjointly to the topics treated during lectures and assigned as homework, the introduction to CAD modeler proceeds with the same scheduling. Every week the $2 \mathrm{H}$ of Practice on CAD is organized as a sequence of two or three steps of growing difficulty around the functionalities of Autodesk Inventor ${ }^{\mathrm{TM}}$. The practice alternates the explanation of a topic and its application, followed by an exercise that may be performed by students. After a certain time (e.g., $20 \mathrm{~min}$ ), the exercise is developed by the instructor. The way proposed online reproduces quite the same one as that of the in-person lecture. The only improvement is the video recording of the events, which aids the practice of the right sequence of steps.

\section{RESULTS AND DISCUSSION}

The comparison of the performances of both didactical methodologies, in-person and online, that have been employed, may suggest some consideration. Data have been collected from the course for Management Engineering that has been delivered in the first semester. Data have been surveyed and compared taking into account two academic years: 2019-2020 (pre-pandemic) and 2020-2021 (pandemic). In Table 1 the following parameters are summarized:

Attending didactics activities. In 2019-2020, an average of 116 students attended the course. In 20202021 , only an estimation of the attending students may be reported, due to some lacking in the right functionality of the software for checking the presence; so, it may be appraised an average of 122 students attending the course. In this second case, it must be considered also an average of 135 visualizations of each recorded lesson.

Attending examination. In 2019-2020, 113 students attended the exam in Jan-Feb 2020. In 2020-2021, 94 students attended the exam in Jan-Feb 2021. This is not a significant decrease because it may be considered that in the Italian academic year scheduling the exams may be faced also at end of the second semester. So, this data cannot be associated with a student dropout, but just with a delay.

Passing examination. In 2019-2020, 73 students passed the exam. In 2020-2021, 70 students passed the exam.

Percentage of passing examination. In 2019-2020, 64.6\%. In 2020-2021, 74.5\%.

Achieved grade (in the 30-point scale). In 2019-2020, an average grade of 25.0. This value is almost similar also with those obtained in the two previous pre-pandemic years. In 2020-2021, an average grade of 27.7 . 
Table 1. Results of the survey on the activities related to the course of "Machine Drawing"

\begin{tabular}{|l|l|l|}
\hline Academic year & $2019-2020$ & $2020-2021$ \\
\hline Attending didactics activities & 116 (certified average) & 122 (esteemed average) \\
\hline Attending examination & 113 & 94 \\
\hline Passing examination & 73 & 70 \\
\hline Percentage of passing examination & $64.6 \%$ & $74.5 \%$ \\
\hline Achieved grade (in the 30-point scale) & 25.0 & 27.7 \\
\hline
\end{tabular}

A certain discordance can be noted for the number of students that attended the didactics activities. In previous years, in presence, the detection happened by a physical device and immediately checked by teachers. Now in online didactics, the attendance may be faked, without any possibility of efficient control.

As it can be seen the new methodology gathers two important outcomes: $10 \%$ of growth in the number of students that passed the exam; $11 \%$ of growth in the grades obtained at the examination. This last result is almost astonishing because introducing other grades, the identification with letters gives a jump from B to A for ECTS grade or a jump from B+ to A for U.S. grade.

This is not associable with a simplification of the exam, because, as for how the exam is conducted, the possibility of cheating is somewhat limited by the effort made by the examiners in requesting and evaluating skills in practical drawing even during the oral phase of the exam.

\section{CONCLUSIONS}

The experience described in the paper and the results discussed may suggest that some online methodologies will remain even when the pandemic emergence will be solved. Some new relationships have been proved more fruitful than in the past, even for a course like Machine Drawing where a certain degree of interaction between teachers and students is necessary. Probably without the forced obligation for online teaching, such kind of methodology would not have been willingly used for the course of Machine Drawing. Perhaps also the massive use of smart working created the right condition for a greater amount of time spent by teachers on didactics.

The results presented are associated with one of the two courses on which the experimentation has been performed. It will be interesting to analyse the same parameters for the course that develops over the whole years, after the examination of the next summer session.

A further element of reflection could be the students' opinion, even in terms of teacher professionalism assessment as in terms of suggestions that students may freely offer for further improvements. In the survey of this year, a set of special requests have been added in order to check the impact of online teaching on students' life.

This work aims to be a stimulus for other colleagues to share similar experiences in order to innovate and/or confirm the methodologies of teaching in a course of Machine Drawing.

\section{REFERENCES}

[1] Dhawan S. Online learning: A panacea in the time of COVID-19 crisis. Journal of Educational Technology Systems, 2020, 49(1), pp. 5-22.

[2] Bhute V. J., Inguva P., Shah U. and Brechtelsbauer C. Transforming traditional teaching laboratories for effective remote delivery - A review. Education for Chemical Engineers, 2021, 35, pp. 96-104.

[3] Szeto E. and Cheng A. Y. N. Towards a framework of interactions in a blended synchronous learning environment: what effects are there on students' social presence experience? Interactive Learning Environments, 2016, 24(3), pp 487-503.

[4] Bao W. COVID-19 and Online Teaching in Higher Education: A Case Study of Peking University. Human Behaviour and Emerging Technologies, 2020, 2, pp. 113-115. 